\title{
High Fidelity BWR Fuel Simulations
}

\author{
Su-Jong Yoon
}

August 2016

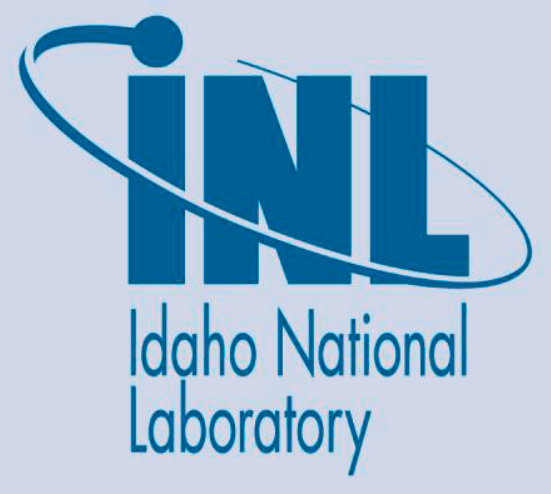

The INL is a U.S. Department of Energy National Laboratory operated by Battelle Energy Alliance 


\section{DISCLAIMER}

This information was prepared as an account of work sponsored by an agency of the U.S. Government. Neither the U.S. Government nor any agency thereof, nor any of their employees, makes any warranty, expressed or implied, or assumes any legal liability or responsibility for the accuracy, completeness, or usefulness, of any information, apparatus, product, or process disclosed, or represents that its use would not infringe privately owned rights. References herein to any specific commercial product, process, or service by trade name, trade mark, manufacturer, or otherwise, does not necessarily constitute or imply its endorsement, recommendation, or favoring by the U.S. Government or any agency thereof. The views and opinions of authors expressed herein do not necessarily state or reflect those of the U.S. Government or any agency thereof. 
INL/EXT-16-39678

Revision 0

\title{
High Fidelity BWR Fuel Simulations (L3 Milestone THM.CFD.P13.03)
}

\author{
Su-Jong Yoon
}

August 2016

Idaho National Laboratory Idaho Falls, Idaho 83415

http://www.inl.gov

Prepared for the

U.S. Department of Energy

Under contract DE-AC05-00OR22725 


\title{
High Fidelity BWR Fuel Simulations (L3 Milestone THM.CFD.P13.03)
}

\author{
Su-Jong Yoon \\ Fusion, Hydrogen and Measurement Sciences \\ Nuclear Science and Technology Division \\ Idaho National Laboratory \\ Idaho Falls, ID 83415
}

\section{EXECUTIVE SUMMARY}

This report describes the Consortium for Advanced Simulation of Light Water Reactors (CASL) work conducted for completion of the Thermal Hydraulics Methods (THM) Level 3 milestone THM.CFD.P13.03: High Fidelity BWR Fuel Simulations.

High fidelity computational fluid dynamics (CFD) simulation for Boiling Water Reactor (BWR) was conducted to investigate the applicability and robustness performance of BWR closures. As a preliminary study, CFD model with simplified ferrule spacer grid geometry of NUPEC BWR Full-size Finemesh Bundle Test (BFBT) benchmark has been implemented. Performance of multiphase segregated solver with baseline boiling closures has been evaluated. Although the mean values of void fraction and exit quality of CFD result for BFBT case 4101-61 well agreed with an experimental data, the local void distribution was not predicted accurately.

The mesh quality was one of the critical factors to obtain converged result of BWR simulation. The stability and robustness of the simulation was affected by both mesh quality and two-phase boiling closures. In addition, the CFD modeling of fully-detailed spacer grid geometry with mixing vane would be necessary for improving the accuracy of CFD simulation in predicting local void distribution. 


\section{CONTENTS}

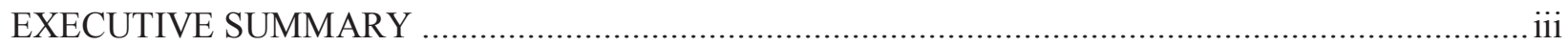

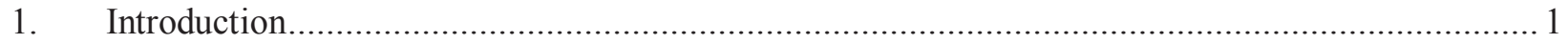

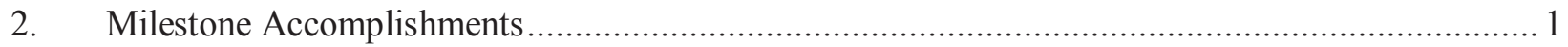

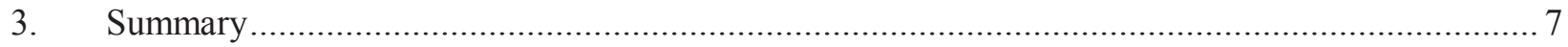

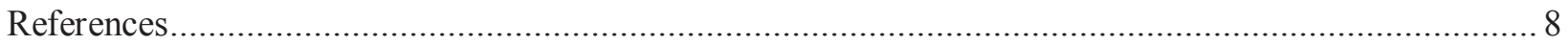

TABLES

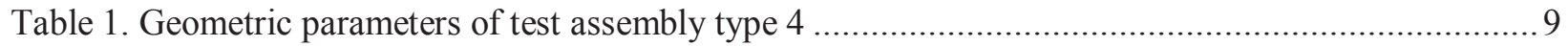

Table 2. Two-phase flow boiling closure models .................................................................... 9

\section{FIGURES}

Figure 1. Estimated grid dimensions for BFBT benchmark [1] .................................................... 10

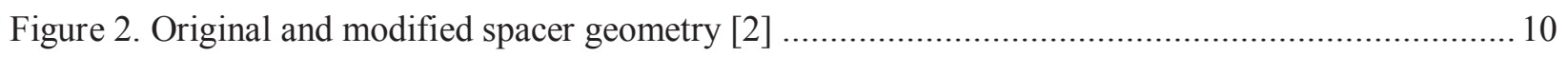

Figure 3. Schematics of geometry and mesh structure of CFD model (unit: mm) ................................ 11

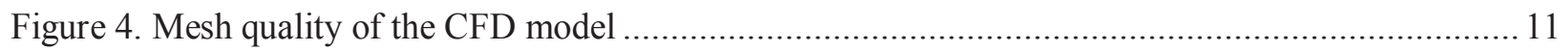

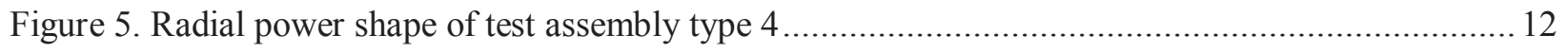

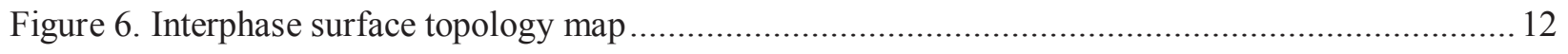

Figure 7. Locations for evaluating sub-channel averaged void fraction............................................ 12

Figure 8. Comparison of void fraction distribution (BFBT 4101-61) ............................................. 13

Figure 9. Deviation of sub-channel averaged void fraction (CFD vs. Experiment) .............................. 13 


\section{Introduction}

The objectives of this milestone are to implement and assess the applicability and robustness performance of the baseline BWR closure models with BWR fuel assembly geometry. The preliminary Best Practice Guidelines (BPG) based on initial experience with baseline closure models was briefly examined. The milestone required completion of the following tasks:

- Identify the representative BWR fuel assembly geometrical details

- Construct a full detail computational fluid dynamics (CFD) model

- Describe and implement the BWR baseline closure models

- Assess BWR closure model performance of full detail validation case.

- Preliminary Best Practice Guidelines

- Submission of this report

Test assembly type 4 with ferrule spacer grid of The NUPEC BWR Full-size Fine-mesh Bundle Test (BFBT) benchmark [1] was selected as BWR fuel assembly geometry for this milestone. The details of tasks mentioned above are discussed in Section 2, and a summary is given in Section 4.

\section{Milestone Accomplishments}

The international OECD/NRC BWR Full-size Fine Mesh Bundle Tests (BFBT) benchmark had conducted to provide the experimental data to assess the accuracy of thermal-hydraulic models for twophase flows in BWR fuel assembly. In this milestone, a detailed CFD model was constructed based on the geometry of $8 \times 8$ high burn-up bundle with ferrule spacer grids (assembly type 4 ). The BFBT $8 \times 8$ high burn-up bundle consists of single water rod in the middle of the assembly and 60 heated rods. The geometric parameters of fuel assembly type 4 are given in Table 1.

The uncertainty in the BFBT fuel assembly geometry had reported in the literatures $[1,2]$. As shown in Fig. 1 [1], the rod pitch was $15.5 \mathrm{~mm}$ and the gap thickness between the spacer and rod was $1.0 \mathrm{~mm}$. The thickness of the spacers reported in this schematic was $0.75 \mathrm{~mm}$. However, according to the ferrule spacer dimensions provided by TEPSYS [1], the rod pitch, rod outer diameters were $15 \mathrm{~mm}$ and $12 \mathrm{~mm}$, respectively. Neykov [2] modified the spacer geometry in his numerical study. As shown in Fig. 2, the rod pitch and outer diameter in his model were $16.2 \mathrm{~mm}$ and $12.3 \mathrm{~mm}$, respectively.

In this study, the CFD model was developed based on the spacer grid geometry constructed by Neykov [2]. Simplified spacer grid geometry was employed as shown in Fig. 3. Dimples and straps of original spacer grid were not included in this model. To prevent poor quality mesh of the sharp gap at the contact point between the spacers, the contact region was modified. The flow area due to this modification was less than $0.1 \%$.

Figure 3 shows the geometry and mesh structure of CFD model. The solid domain for spacer grid was implemented in this model to account for the heat conduction through the spacer grid. In total, 21.6 million hexahedral meshes were used in this CFD model. The mesh quality in two-phase flow boiling simulation had significant influence on the stability and robustness of the simulation. The poor quality mesh structure should be avoided because the simulation was crashed due to too high or low temperature calculated at the poor cell. The point contact or line contact in CFD model results in very poor quality 
mesh around those contacts. Consequently, the mesh structure for fuel assembly geometry should be constructed appropriately to avoid having the involuntary geometric features. Replacing point contact or line contact in geometry with an approximated surface contact could be a good solution to improve mesh quality. Figure 4 shows the mesh quality at the cross-section of the computational domain. The minimum mesh quality of this model was 0.367 and the volume-averaged mesh quality of solid and fluid domains were 0.997 and 0.975 , respectively.

The boundary conditions of CFD model were implemented from the test conditions of BFBT test 4101-61. The uniform axial power and non-uniform radial power distribution were specified as shown in Fig. 5. Total power of the BFBT test 4101-61 case was $6.48 \mathrm{MW}$. The inlet mass flow rate was $15.28 \mathrm{~kg} / \mathrm{s}$. The inlet velocity profile was specified from the velocity profile at the outlet of single-phase flow simulation. Single-phase CFD simulation without spacer grids was conducted to get the fully-developed velocity profile for two-phase flow simulation. Operating pressure was specified by $7.159 \mathrm{MPa}$. Inlet liquid and vapor temperatures were specified by $551.096 \mathrm{~K}$ and $560.538 \mathrm{~K}$, respectively.

The multiphase segregated flow solver in STAR-CCM+ code [3] was employed to solve a set of conservation equations for each Eulerian phase. The conservation equations of mass, momentum and energy for generic phase $i$ are given by:

- Continuity equation

$$
\frac{\partial}{\partial t} \int_{V} \alpha_{i} \rho_{i} \chi d V+\oint_{A} \alpha_{i} \rho_{i} \chi\left(\mathbf{v}_{i}-\mathbf{v}_{g}\right) \cdot d \mathbf{a}=\int_{V} \sum_{j \neq i}\left(m_{i j}-m_{j i}\right) \chi d V+\int_{V} S_{i}^{\alpha} d V
$$

where $\alpha_{i}$ is the volume fraction of phase $i, \rho_{i}$ is the density of phase $i, \chi$ is the void fraction, $\mathbf{v}_{i}$ is the velocity of phase $i, \mathbf{v}_{g}$ is the grid velocity, $m_{i j}$ is the mass transfer rate to phase $i$ from phase $j\left(m_{i j} \geq 0\right), m_{j i}$ is the mass transfer rate to phase $j$ from phase $i\left(m_{j i} \geq 0\right)$ and $S_{i}^{\alpha}$ is the phase mass source term. The sum of the volume fractions is 1.0 .

- Momentum conservation equation

$$
\begin{aligned}
& \frac{\partial}{\partial t} \int_{V} \alpha_{i} \rho_{i} \chi \mathbf{v}_{\boldsymbol{i}} d V+\oint_{A} \alpha_{i} \rho_{i} \chi \mathbf{v}_{\boldsymbol{i}} \otimes\left(\mathbf{v}_{i}-\mathbf{v}_{g}\right) \cdot d \mathbf{a}=-\int_{V} \alpha_{i} \chi \nabla p d V+\int_{V} \alpha_{i} \rho_{i} \chi \mathbf{g} d V \\
& +\oint_{A}\left[\alpha_{i}\left(\tau_{i}+\tau_{i}^{t}\right)\right] \chi \cdot d \mathbf{a}+\int_{V} \mathbf{M}_{i} \chi d V+\int_{V}\left(\mathbf{F}_{\text {int }}\right)_{i} \chi d V+\int_{V} \mathbf{S}_{i}^{\mathrm{V}} d V+\int_{V} \Sigma\left(m_{i j} \mathbf{v}_{j}-m_{j i} \mathbf{v}_{i}\right) \chi d V
\end{aligned}
$$

where $p$ is the pressure, assumed to be equal in both phases, $\mathbf{g}$ is the gravity vector, $\tau_{i}$ and $\tau_{i}^{t}$ is the molecular and turbulent stresses, respectively, $\mathbf{M}_{\mathrm{i}}$ is the interphase momentum transfer per unit volume, $\left(\mathbf{F}_{\text {int }}\right)_{i}$ represents internal forces, $\mathbf{S}_{i}^{\mathrm{v}}$ is the phase momentum source term, $m_{i j}$ is the mass transfer rate from phase $j$ to phase $i$ and $m_{j i}$ is the mass transfer rate from phase $i$ to phase $j$. The interphase momentum transfer term $\left(\mathbf{M}_{i}\right)$ in Eqn. (2) includes contributions from the drag, virtual mass, lift and turbulent dispersion forces as follows:

$$
\mathrm{M}_{\mathrm{i}}=\sum_{\mathrm{j} \neq \mathrm{i}}\left(\mathrm{F}_{\mathrm{ij}}^{\mathrm{D}}+\mathrm{F}_{\mathrm{ij}}^{\mathrm{VM}}+\mathrm{F}_{\mathrm{ij}}^{\mathrm{L}}+\mathrm{F}_{\mathrm{ij}}^{\mathrm{TD}}+\boldsymbol{F}_{i j}^{W L}\right)
$$

where $\mathbf{F}_{i j}$ is the force per cell volume, on phase $i$, due to phase $j$.

To solve the momentum conservation equation of multiphase flow, the constitutive models for drag force, virtual mass force, lift force and turbulent dispersion force in Eqn. (3) are required. The drag force is calculated as follows:

$$
\boldsymbol{F}_{i j}^{D}=C_{D} \frac{1}{2} \rho_{c}\left(\mathbf{v}_{j}-\mathbf{v}_{i}\right)^{2}\left(\frac{a_{i j}}{4}\right)
$$

where $a_{i j}$ is the interfacial area density which represents the projected area of the equivalent spherical particle, and $C_{D}$ is the drag coefficient. In this study, the drag coefficient was determined by combination 
of Schiller-Naumann method [4] for bubbly flow $\left(\alpha_{g} \leq 0.5\right)$ and empirical correlation [5] for mist flow $\left(\alpha_{g}>0.5\right)$ as follows:

$$
\begin{array}{ll}
\alpha_{g} \leq 0.5: & C_{D}=\left\{\begin{array}{lr}
\frac{24}{R e}\left(1+0.15 R e^{0.687}\right) & 0 \leq R e \leq 1,000 \\
0.44 & R e>1,000
\end{array}\right. \\
\alpha_{g}>0.5: & C_{D}=\frac{24}{R e}+\frac{5.48}{R e^{0.573}}+0.36
\end{array}
$$

The particle submerged in the flow would be accelerated due to the inertia of surrounding fluid and this effect can be represented as a "virtual mass" or "added mass" equal to a constant multiplied by the mass of fluid that the particle displaces. A two-phase formulation for the virtual mass force [6] is given by:

$$
\boldsymbol{F}_{i j}^{V M}=C_{i j}^{V M} \alpha_{d} \rho_{c}\left[\frac{D \boldsymbol{u}_{c}}{D t}-\frac{D \boldsymbol{u}_{d}}{D t}\right]
$$

where $\mathbf{v}_{\mathrm{c}}$ and $\mathbf{v}_{\mathrm{d}}$ are the fluid velocity of continuous phase and dispersed phase, respectively, and the virtual mass coefficient for spherical $\operatorname{particle}\left(C_{i j}^{V M}\right)$ is 0.5 .

The lift force perpendicular to the relative velocity due to the non-uniform or swirling two-phase flow field is determined as follows:

$$
\boldsymbol{F}_{L}=C_{L} \alpha_{d} \rho_{c}\left[\boldsymbol{u}_{r} \times\left(\nabla \times \boldsymbol{u}_{r}\right)\right]
$$

where $\boldsymbol{u}_{\mathrm{r}}$ is the relative velocity between the continuous phase and dispersed phase $\left(\boldsymbol{u}_{c}-\boldsymbol{u}_{d}\right)$. OhnukiAkimoto correlation for the lift coefficient [7] was implemented in this study as follows:

$$
\begin{aligned}
& C_{L}=C_{L F}+C_{W K} \\
& C_{L F}=0.288 \tanh (0.121 R e) \\
& C_{W K}=\left\{\begin{array}{lr}
0 & E o \leq 4 \\
-0.096 E o+0.384 & 4<E o \leq 10 \\
-0.576 & E o>10
\end{array}\right.
\end{aligned}
$$

where $E o$ is Eötvös number.

Turbulent dispersion force is to account for the effect of turbulence in redistribution of nonuniformities in phase concentration. The turbulent dispersion force term is given by:

$$
\boldsymbol{F}_{T D}=A_{D} \frac{v_{c}^{t}}{\sigma_{\alpha}}\left(\frac{\nabla \alpha_{d}}{\alpha_{d}}-\frac{\nabla \alpha_{c}}{\alpha_{c}}\right)
$$

where $v_{c}{ }_{c}^{t}$ is the continuous phase turbulent kinematic viscosity, $\sigma_{\alpha}$ is the turbulent Prandtl number of the volume fraction. Constant turbulent Prandtl number of 0.9 was specified in this study.

The fluid asymmetrically flowing around the bubble near a wall results in the force which prevents the bubbles from touching the wall. This force term is so-called "Wall Lubrication force." The modified Antal model [8] based on flow topology map [9] for the wall lubrication force term is given by:

$$
\begin{aligned}
& \boldsymbol{F}_{W L}=\xi_{d} \zeta_{d} \frac{\alpha_{d} \rho_{c} \boldsymbol{u}_{r}^{2}}{d} \max \left(C_{1}+C_{2} \frac{d}{y_{w}}, 0\right) n_{w} \\
& \xi_{d}=\left\{\begin{array}{lr}
1 & \alpha \leq \alpha_{g, b c} \\
\frac{1}{2}\left(1-\cos \left(\pi \frac{\alpha-\alpha_{g, c m}}{\alpha_{g, c m}-\alpha_{g, b c}}\right)\right) & \alpha_{g, b c}<\alpha \leq \alpha_{g, c m} \\
0 & \alpha_{g, c m}<\alpha
\end{array}\right.
\end{aligned}
$$




$$
\zeta_{d}= \begin{cases}1 & \gamma \leq \gamma_{1} \\ \frac{1}{2}\left(1-\cos \left(\pi \frac{\gamma-\gamma_{2}}{\gamma_{2}-\gamma_{1}}\right)\right) & \gamma_{1}<\gamma \leq \gamma_{2} \\ 0 & \gamma_{2}<\gamma\end{cases}
$$

where $y_{w}$ is distance to the nearest wall and $n_{w}$ is the unit normal pointing away from the wall, model constants $C_{1}$ and $C_{2}$ are -0.01 and 0.05 , respectively. The interphase surface topology map is used to determine the flow regime in conjunction with the local void fraction $(\alpha)$ and void fraction differential $(\gamma)$. Figure XX shows the flow topology map. The values of $\alpha_{g, b c}, \alpha_{g, c m}, \gamma_{1}$ and $\gamma_{2}$ were specified by $0.3,0.7$, 0.2 and 0.4 , respectively.

The realizable $k-\varepsilon$ two-layer turbulent model with all $\mathrm{y}^{+}$wall treatment was employed for both continuous phase and dispersed phase. Details of Realizable k- $\varepsilon$ Two-layer turbulent model can be found in the literature [3]. To account for the bubble induced turbulence effect, Troskho-Hassan particle induced turbulence model [10] was employed.

- Energy conservation equation

$$
\begin{aligned}
& \frac{\partial}{\partial t}\left(\alpha_{i} \rho_{i} E_{i}\right)+\nabla \cdot\left[\alpha_{i} \rho_{i} H_{i}\left(\mathbf{v}_{i}-\mathbf{v}_{g}\right)\right]+\nabla \cdot \alpha_{i} \mathbf{v}_{\mathrm{g}} p=\nabla \cdot\left(\alpha_{i} k_{e f f, i} \Delta T_{i}\right)+\nabla \cdot\left(\mathbf{T}_{i} \cdot \mathbf{v}_{i}\right) \\
& +\mathbf{f}_{i} \cdot \mathbf{v}_{i}+\sum_{\mathrm{j} \neq \mathrm{i}} Q_{i j}+\sum_{(\mathrm{ij})} Q_{i}^{(i j)}+S_{u, i}+\sum_{\mathrm{j} \neq \mathrm{i}}\left(m_{i j}-m_{j i}\right) h_{i}\left(T_{i j}\right)
\end{aligned}
$$

where $\mathrm{E}_{i}$ is the total energy, $\mathrm{H}_{i}$ is the total enthalpy, $\mathbf{T}_{i}$ is the viscous stress tensor, $\alpha_{i}, \rho_{i}$ and $\mathbf{v}_{i}$ are the volume fraction, density and velocity of phase $i$, respectively, $T_{i}$ is the temperature, $k_{\text {eff,i } i}$ is the effective thermal conductivity, $\mathbf{f}_{i}$ is the body force vector, $Q_{i j}$ is the interphase heat transfer rate to phase $i$ from phase $j, Q_{i}{ }^{i j)}$ is the heat transfer rate to phase $i$ from phase pair interface $(i j), S_{u, i}$ is the energy source, $h_{i}\left(T_{i j}\right)$ is the phase $i$ enthalpy that is evaluated at the interface temperature $T_{i j}$.

The effective thermal conductivity, $k_{\text {eff }}$ is given by:

$$
k_{e f f, i}=k_{i}+\frac{\mu_{t, i} C_{p, i}}{\sigma_{t, i}}
$$

where $k_{i}$ is the thermal conductivity, $\mu_{t, i}$ is the turbulent viscosity, $C_{p, i}$ is the specific heat and $\sigma_{t, i}$ is the turbulent thermal diffusion Prandtl number.

The relationship between the total energy $(E)$ and total enthalpy $(H)$ is given by:

$$
E_{i}=H_{i}-\frac{p}{p_{i}}
$$

where the total enthalpy is determined by:

$$
H_{i}=h_{i}+\frac{\left|\mathbf{v}_{i}\right|^{2}}{2}
$$

and

$$
h_{i}\left(T_{i}\right)=h_{i}^{R E F}+\int_{T_{i}^{R E F}}^{T_{i}} C_{p, i}\left(T^{\prime}\right) d T^{\prime}
$$

where $h_{i}^{R E F}$ is the heat of formation for phase $i$ and $T_{i}^{R E F}$ is the standard state temperature.

In the multiphase segregated flow solver of STAR-CCM+ code, the GEN-I boiling closure models were implemented [11]. In addition, the user-coded function and field function of STAR-CCM+ allow users to implement any other boiling closure models. In this work, the two-phase flow boiling models were implemented by using default GEN-I boiling closure models and user-coded field function. The two-phase flow boiling closure models implemented in this work was summarized in Table 2. 
The interaction length scale is used to determine an effective mean diameter of the dispersed phase particles. In the two-phase flow, the interaction length scale represents the bubble diameter. In this test, Kurul-Podowski interaction length scale was employed as follows:

$$
l_{c d}=\frac{D_{\min }\left(\Delta T_{D, \max }-\Delta T\right)+D_{\max }\left(\Delta T-\Delta T_{D, \min }\right)}{\Delta T_{D, \max }-\Delta T_{D, \min }}
$$

where $D_{\min }$ and $D_{\max }$ are the minimum and maximum bubble diameters, respectively, with default values of $0.15 \mathrm{~mm}$ and $2.0 \mathrm{~mm} . \Delta T_{D, \min }$ is liquid subcooling corresponding to the minimum bubble diameter with a default value of $13.5 \mathrm{~K}$ and $\Delta T_{D, \max }$ is the liquid subcooling corresponding to the maximum bubble diameter with a default value of $-5.0 \mathrm{~K}$.

Interaction area density specifies the interfacial area which is used to determine drag force, heat and mass transfer between each pair of phase. Spherical particle interaction area density was employed as follows:

$$
a_{c d}=\frac{6 \alpha_{d}}{l_{c d}}
$$

When the vapor volume fraction adjacent to the wall becomes high enough so that the liquid access is restricted, the vapor heat transfer removes some fraction of the wall heat flux. The wall dryout area fraction is used to determine the heat flux by the vapor as follows:

$$
\dot{q}_{w}^{\prime \prime}=\left(\dot{q}_{c o n v}^{\prime \prime}+\dot{q}_{\text {evap }}^{\prime \prime}+\dot{q}_{q u e n c h}^{\prime \prime}\right)\left(1-K_{d r y}\right)+K_{d r t} \dot{q}_{d r y}^{\prime \prime}
$$

where $\dot{q}_{d r y}^{\prime \prime}$ is the vapor contribution to the convective heat flux based on single-phase turbulent convection by the vapor and $K_{d r y}$ is the wall contact area fraction for the vapor.

The wall contact area fraction $\left(K_{d r y}\right)$ is given by:

$$
K_{d r y}= \begin{cases}0 & \alpha_{\delta} \leq \alpha_{d r y} \\ \left(\frac{3-2 \alpha_{\delta}-\alpha_{d r y}}{1-\alpha_{d r y}}\right)\left(\frac{\alpha_{\delta}-\alpha_{d r y}}{1-\alpha_{d r y}}\right)^{2} & \alpha_{\delta}>\alpha_{d r y}\end{cases}
$$

where $\alpha_{\delta}$ is the vapor volume fraction averaged over the bubbly layer thickness, and $\alpha_{d r y}$ is the wall dryout breakpoint with a default value of 0.9 .

The evaporative heat flux in Eqn. (22) is determined as follows:

$$
\dot{q}_{\text {evap }}^{\prime \prime}=n^{\prime \prime} f\left(\frac{\pi d_{w}^{3}}{6}\right) \rho_{g} h_{l g}
$$

where $n$ " is the nucleation site number density, $f$ is the bubble departure frequency, $d_{w}$ is the bubble departure diameter, $\rho_{g}$ is the vapor phase density and $h_{l g}$ is the latent heat.

The modified Lemmert-Chawla nucleation site number density model [12] was employed as follows:

$$
\frac{n^{\prime \prime}}{n_{0}^{\prime \prime}}=\left(\frac{\Delta T_{s u b}}{\Delta T_{0}}\right)^{A+B\left(\Delta T / \Delta T_{0}\right)}
$$

where $\mathrm{A}$ and $\mathrm{B}$ are calibration constants with default values of 1.805 and 0.0 , respectively, $n_{0}$. is the reference nucleation site number density with a default value of $12366.447831 / \mathrm{m}^{2}$ and $\Delta T_{0}$ is the reference wall superheat with a default value of $25 \mathrm{~K}$.

Cole bubble departure frequency model [13] was employed as follows:

$$
f=\sqrt{\frac{4}{3} \frac{g\left(\rho_{l}-\rho_{g}\right)}{d_{w} \rho_{l}}}
$$

The Kocamustafaogullari bubble departure diameter [14] was employed as follows: 


$$
d_{w}=d_{1} \theta\left(\frac{\sigma}{g \Delta \rho}\right)^{0.5}\left(\frac{\Delta \rho}{\rho_{g}}\right)^{0.9}
$$

Where $d_{l}$ is a calibration constant with a default value of $1.5236 \times 10^{-3} \mathrm{~m} / \mathrm{rad}, \theta$ is the wall contact angle with a default value of $0.722 \mathrm{rad}, \sigma$ is the surface tension, $\Delta \rho$ is the difference in density between the liquid and gas phase, and $\rho_{g}$ is the vapor phase density.

The quenching heat flux in Eqn. (22) is determined as follows:

$$
\dot{q}_{\text {quench }}=h_{\text {quench }}\left(T_{w}-T_{\text {quench }}\right)
$$

where $h_{\text {quench }}$ is the quenching heat transfer coefficient, $T_{w}$ is the wall temperature and $T_{\text {quench }}$ is the temperature at which liquid brought to the wall by the departure of a bubble.

The Del Valle Kenning model [15] was used to determine the quenching heat transfer coefficient as follows:

$$
h_{\text {quench }}=2 K_{\text {quench }} f \sqrt{\frac{\rho_{l} c_{p l} k_{l} t_{w}}{\pi}}
$$

where $K_{\text {quench }}$ is the bubble influence wall area fraction, $f$ is the bubble departure frequency, $t_{w}$ is the waiting time between the bubble departure and the nucleation of the next bubble.

The Kurul-Podowski bubble influence wall area fraction model [16] was employed as follows:

$$
K_{\text {quench }}=F_{A} \frac{\pi d_{w}^{2}}{4} n^{\prime \prime}
$$

where $F_{A}$ is the area coefficient for scaling between the nucleation site area density and the wall fraction the bubble-induced quenching influences with a default value of 2.0.

The boiling mass transfer rate model is used to model the rate of bulk boiling or condensation between phases. For a dispersed phase, a constant Nusselt number was specified by 2.0. For a continuous phase, Chen and Mayinger condensation model [17] was implemented to determine the phase Nusselt number as follows:

$$
\mathrm{Nu}_{c 0}=0.185 \operatorname{Re}_{b 0}^{0.7} \operatorname{Pr}_{f}^{0.5}
$$

where the Nusselt number and Reynolds numbers are defined in terms of the initial bubble diameter.

The exit quality and sub-channel averaged void fraction distribution were analyzed to assess the capability of STAR-CCM+ code. Figure 7 shows the locations of sub-channels for the data analysis. The mean value of sub-channel averaged void fraction of experimental data was $80.64 \%$. The CFD simulation result slightly overestimated the mean value of sub-channel averaged void fraction by $85.53 \%$. The void fractions in the middle region of CFD result was relatively lower than those in the outer region as shown in Fig. 8. The void fractions in outer region were higher than inner region because the radial power in outer region was higher than the inner region. In addition the simplified spacer grid geometry without the mixing vane would have an influence on the local void distribution. Therefore, the flow mixing effect due to the mixing vane geometry need to be investigated in the future study.

Figure 9 shows the deviation of the sub-channel averaged void fraction between the CFD result and experimental data. The maximum error in sub-channel averaged void fraction between the CFD result and experimental data was $20.38 \%$ at the outer corner of the BFBT fuel assembly. The mean value of deviation of void fraction was $4.89 \%$. The thermal equilibrium quality at the outlet agreed with each other. The exit quality of CFD result was $26.26 \%$ which slightly overestimated the experimental data of $25 \%$. 


\section{Summary}

High fidelity CFD simulation for BWR fuel assembly has been conducted with a multiphase segregated flow solver of STAR-CCM+ code. CFD model of BWR fuel assembly was modeled based on the NUPEC BFBT fuel assembly geometry. The baseline two-phase flow boiling closure models were implemented in this CFD model. The high quality hexahedral mesh was generated for the computational domain. The poor quality mesh structure had a significant influence on the stability and robustness of the simulation. It is noted that poor quality mesh resulted in the critical convergence issue of the simulation.

Although the mean values of void fraction and thermal equilibrium quality by the CFD simulation agreed with the experimental data in this work, the CFD capability for predicting local void distribution was not sufficient. The full detailed modeling of mixing vane geometry seems to be necessary to improve the CFD result.

This research was supported by the Consortium for Advanced Simulation of Light Water Reactor (www.casl.gov), an Energy Innovation hub (http://www.energy.gov/hubs) for Modeling and Simulation of Nuclear Reactors under U.S. Department of Energy Contract No. DE-AC05-00OR22725. 


\section{References}

[1] Neykov, B., Aydogan, F., Hochreiter, L., Ivanov, K., Utsuno, H., Kasahara, K., Sartori, E. and Martin, M., 2006. "NUPEC BWR Full-size Fine-mesh Bundle Test (BFBT) benchmark, Volume I: Specification,” OECD, Nuclear Energy Agency, NEA No. 6212, ISBN 92-64-01088-2.

[2] Neykov, B., 2010. "Development and validation of advanced CFD models for detailed predictions of void distribution in a BWR bundle," Ph.D dissertation, The Pennsylvania State University.

[3] CD-Adapco. 2016. STAR-CCM+ Users Guide, https://stevedocs.cd-adapco.com/, accessed on August 182016.

[4] Schiller, L., and Naumann, A. 1933. Uber die grundlegenden Berechnungen bei der Schwerkraftaufbereitung, VDI Zeits, 77(12), pp. 318-320.

[5] Lo, S. Modeling multiphase flow with an Eulerian approach, Belgium : von Karman Institute Lecture Series - Industrial two-phase flow CFD, May 23-27, 2005

[6] Auton, T.R., Hunt, J.C.R., and Prud'homme, M. 1988. The force exerted on a body in inviscid unsteady non-uniform rotational flow, J. Fluid Mech., 197, pp. 241-257.

[7] Ohnuki, A., Akimoto, H. 2001. Model development for bubble turbulent diffusion and bubble diameter in large vertical pipes, J. Nucl. Sci. Technol., 38 (12), 1074-1080.

[8] Antal, S. P., Lahey, R. T., and Flaherty, J. E. 1991. Analysis of phase distribution in fully developed laminar bubbly two-phase flow, Int. J. Multiphase Flow, 17, pp. 635-652.

[9] Tentner, A., Lo, S., Ioilev, A., Samigulin, M., Ustinenko, V. 2005. "Computational fluid dynamics modeling of two-phase flow in a boiling water reactor fuel assembly," American Nuclear Society Topical Meeting in Mathematics \& Computations, Avignon, France, September 12-15.

[10] Troshko, A. A. and Hassan, Y. A. 2001. A two-equation turbulence model of turbulent bubbly flows, Int. J. Multiphase Flow, 27 pp. 1965-2000.

[11] Baglietto, E., Christon, M.A., 2013. "Demonstration \& assessment of advanced modeling capabilities for multiphase flow with sub-cooled boiling," CASL-U-2013-0181-001.

[12] Lemmert, M. and Chawla, J.M. 1977. "Influence of flow velocity on surface boiling heat transfer coefficient”, In: E. Hahne and U. Grigull, Eds., Heat Transfer in Boiling, Academic Press and Hemisphere, New York, NY, USA.

[13] Cole R. 1960. "A photographic study of pool boiling in the region of the critical heat flux", AIChE J., 6, pp. 533-542.

[14] Kocamustafaogullari G., 1983. Pressure dependence of bubble departure diameter for water, Int. Comm. Heat Mass Transfer, 10, pp. 501-509.

[15] Del Valle M.V.H. and Kenning D.B.R. 1985. Subcooled flow boiling at high heat flux, Int. J. Heat Mass Transfer, 28, pp. 1907-1920.

[16] Kurul, N. and Podowski, M.Z. 1990. "Multidimensional effects in sub-cooled boiling", Proceedings of the Ninth Heat Transfer Conference, Jerusalem.

[17] Chen, Y., Mayinger, F., 1992. Measurement of heat transfer at the phase interface of condensing bubbles, Int. J. Multiphase Flow, 18 (6), 877-890. 
Table 1. Geometric parameters of test assembly type 4

\begin{tabular}{|l|l|}
\hline Parameters & Data \\
\hline Simulated fuel assembly type & High Burn-up $8 \times 8$ \\
\hline Number of heated rods & 60 \\
\hline Heated rod outer diameter $(\mathrm{mm})$ & 12.3 \\
\hline Heated rod pitch $(\mathrm{mm})$ & 16.2 \\
\hline Axial heated length $(\mathrm{mm})$ & 3708 \\
\hline Water rod outer diameter $(\mathrm{mm})$ & 34.0 \\
\hline Channel box inner width $(\mathrm{mm})$ & 132.5 \\
\hline Channel box corner radius $(\mathrm{mm})$ & 8.0 \\
\hline In channel flow area $\left(\mathrm{mm}^{2}\right)$ & 9463 \\
\hline Spacer type & Ferrule \\
\hline $\begin{array}{l}\text { Spacer location (distance from bottom of heated length } \\
\text { to spacer bottom face) }(\mathrm{mm})\end{array}$ & $455,967,1479,1991,2503,3015,3527$ \\
\hline Radial power shape & A \\
\hline Axial power shape & Uniform \\
\hline
\end{tabular}

Table 2. Two-phase flow boiling closure models

\begin{tabular}{|l|l|}
\hline Parameters & Model \\
\hline Condensation-Fluid & Chen-Mayinger \\
\hline Condensation-Vapor & $\mathrm{Nu}=2.0$ \\
\hline Bubble induced quenching temperature & Wall Cell \\
\hline Bubble departure frequency & Cole \\
\hline Bubble induced quenching heat transfer coefficient & Del Valle Kenning (Wait coefficient: 0.8) \\
\hline Bubble influence wall area fraction & Kurul-Podowski (Area coefficient: 2.0 ) \\
\hline Nucleation site number density & Lemmert-Chawla \\
\hline Bubble departure diameter & Kocamustafaogullari \\
\hline Interaction length scale & Kurul-Podowski \\
\hline Interaction area density & Spherical \\
\hline Lift force & Ohnuki \& Akimoto \\
\hline Drag force & Schiller \& Naumann + empirical correlation \\
\hline Turbulent dispersion & Favre Averaged Drag Turbulent Pr $=0.9$ \\
\hline Virtual mass & Auton (Spherical particle) \\
\hline Wall lubrication & Modified Antal \\
\hline
\end{tabular}




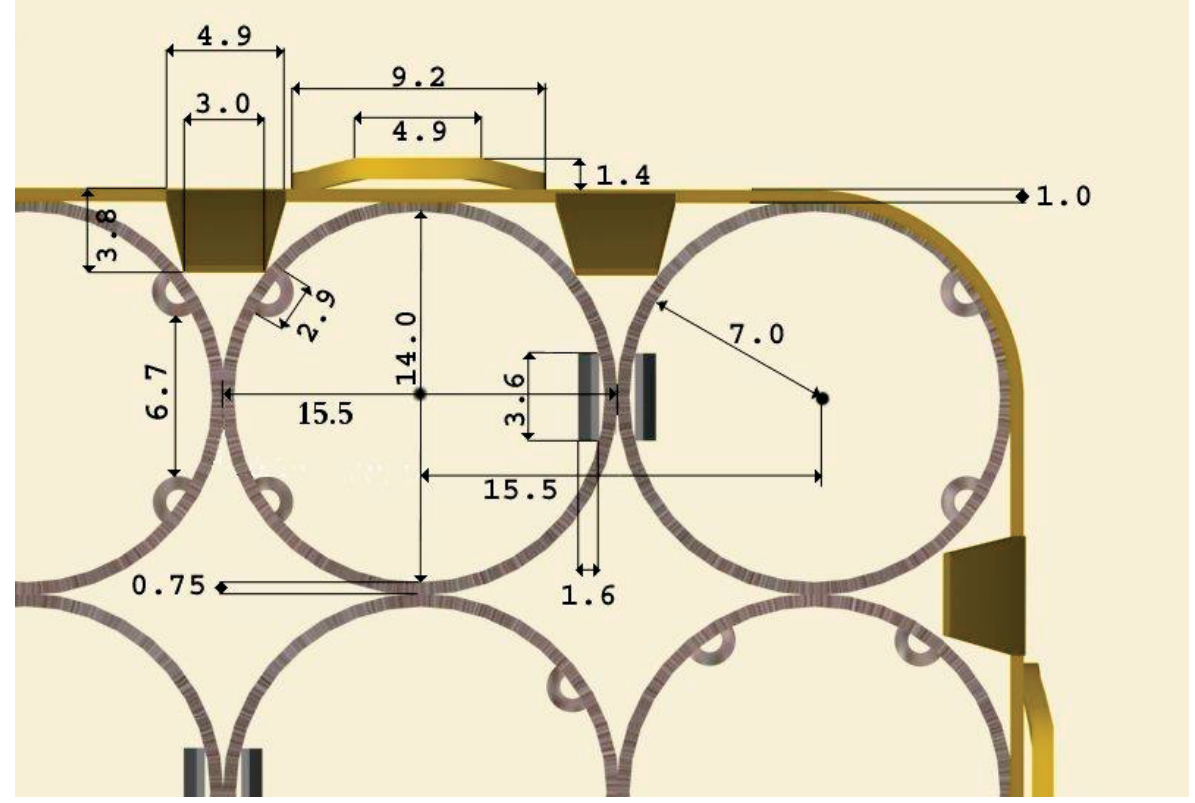

Figure 1. Estimated grid dimensions for BFBT benchmark [1]
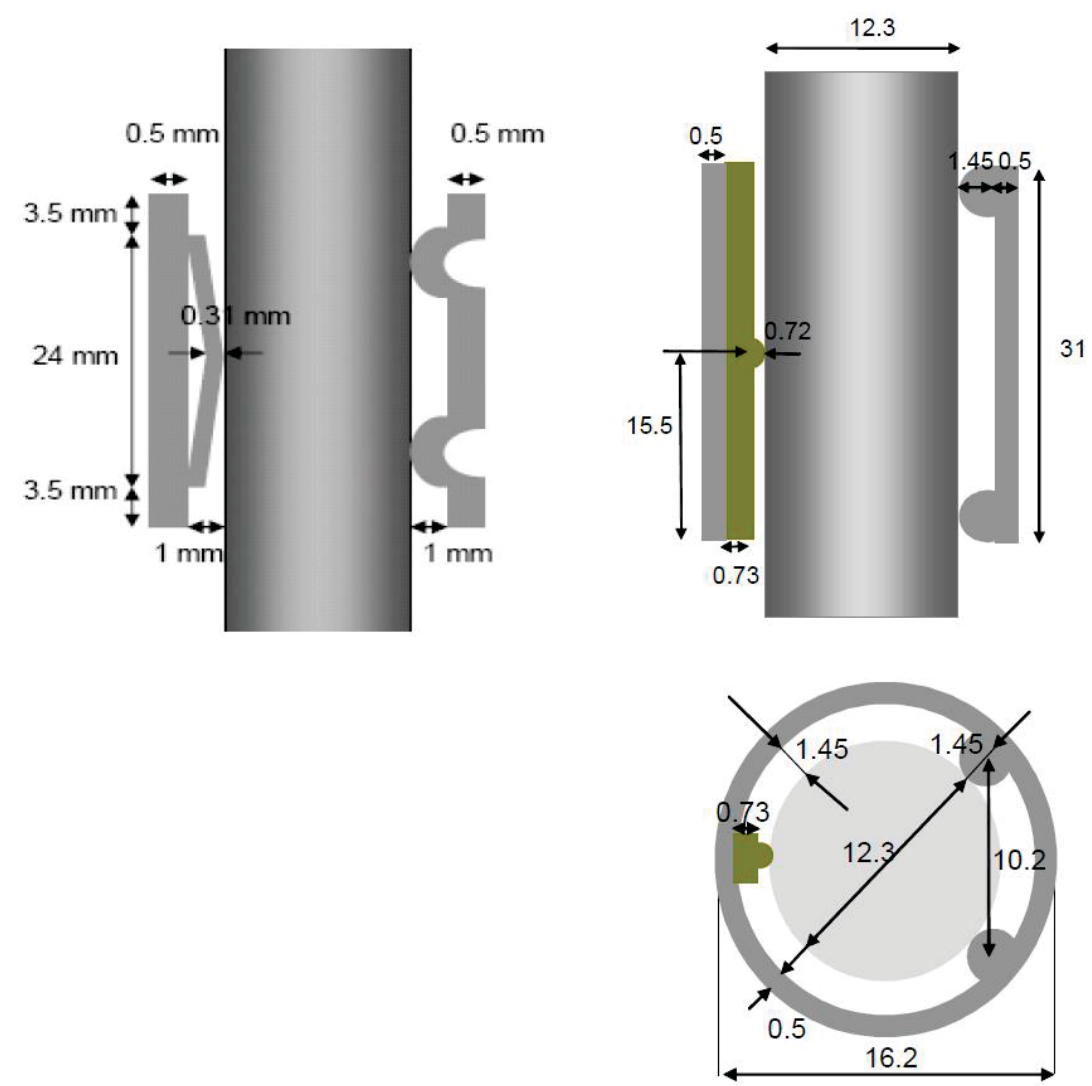

Figure 2. Original and modified spacer geometry [2] 


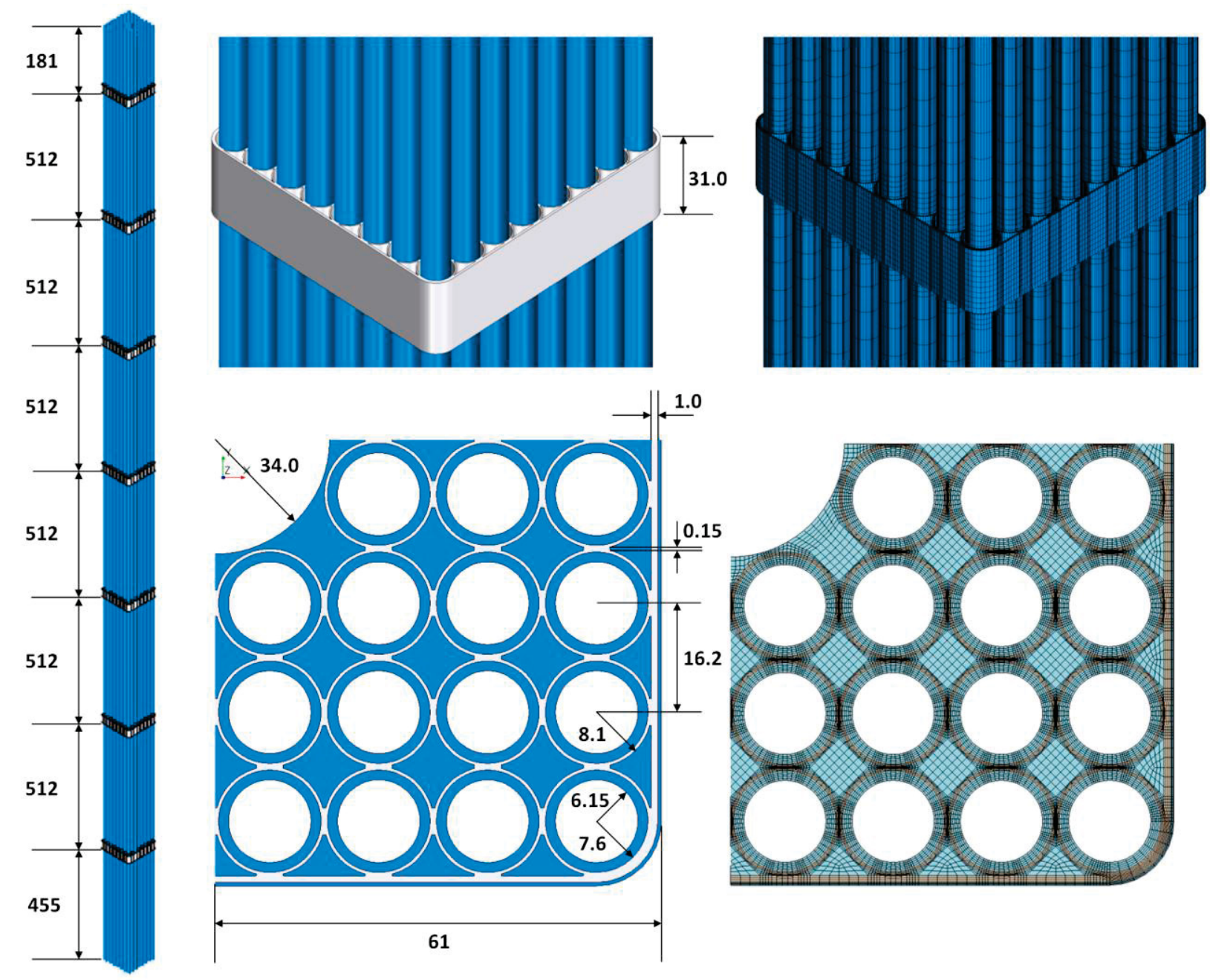

Figure 3. Schematics of geometry and mesh structure of CFD model (unit: mm)

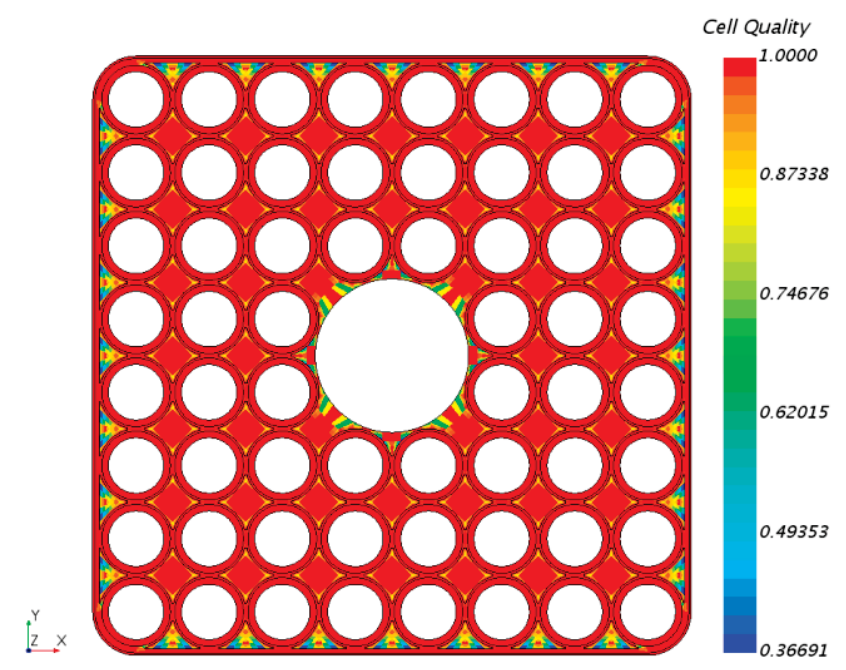

Figure 4. Mesh quality of the CFD model 
A (for Assembly 4, C2A, C3)

\begin{tabular}{|c|c|c|c|c|c|c|c|}
\hline 1.15 & 1.30 & 1.15 & 1.30 & 1.30 & 1.15 & 1.30 & 1.15 \\
\hline 1.30 & 0.45 & 0.89 & 0.89 & 0.89 & 0.45 & 1.15 & 1.30 \\
\hline 1.15 & 0.89 & 0.89 & 0.89 & 0.89 & 0.89 & 0.45 & 1.15 \\
\hline 1.30 & 0.89 & 0.89 & & & 0.89 & 0.89 & 1.15 \\
\hline 1.30 & 0.89 & 0.89 & & & 0.89 & 0.89 & 1.15 \\
\hline 1.15 & 0.45 & 0.89 & 0.89 & 0.89 & 0.89 & 0.45 & 1.15 \\
\hline 1.30 & 1.15 & 0.45 & 0.89 & 0.89 & 0.45 & 1.15 & 1.30 \\
\hline 1.15 & 1.30 & 1.15 & 1.15 & 1.15 & 1.15 & 1.30 & 1.15 \\
\hline
\end{tabular}

Figure 5. Radial power shape of test assembly type 4

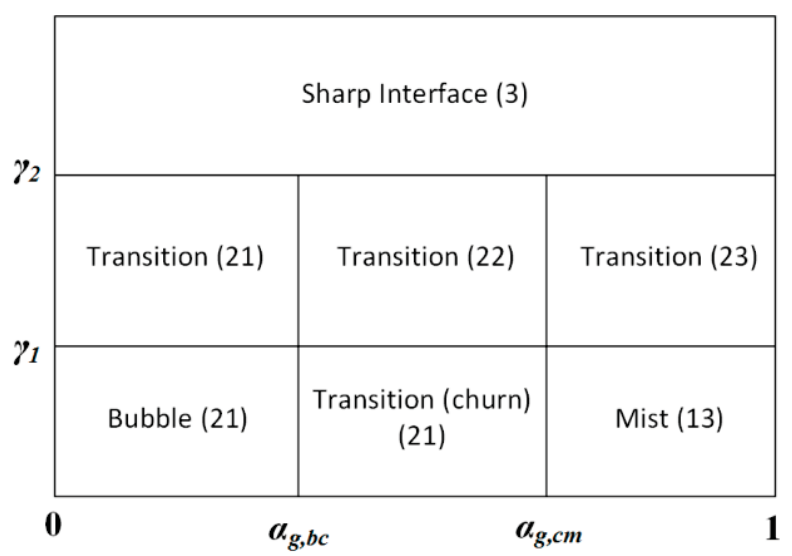

Figure 6. Interphase surface topology map

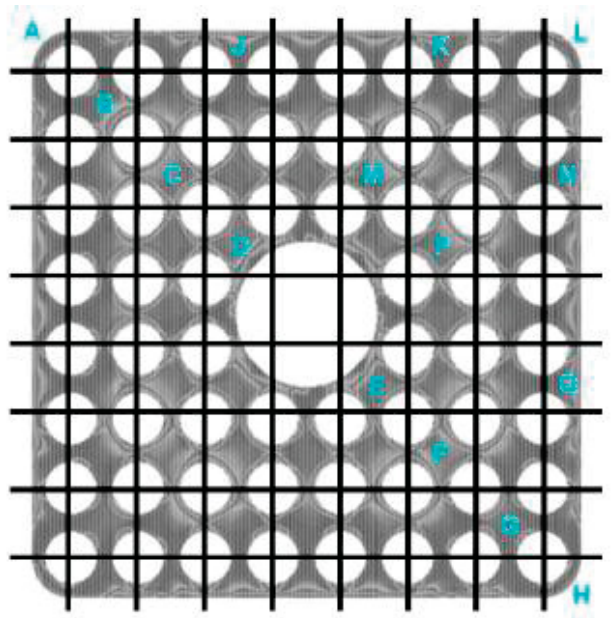

Figure 7. Locations for evaluating sub-channel averaged void fraction 


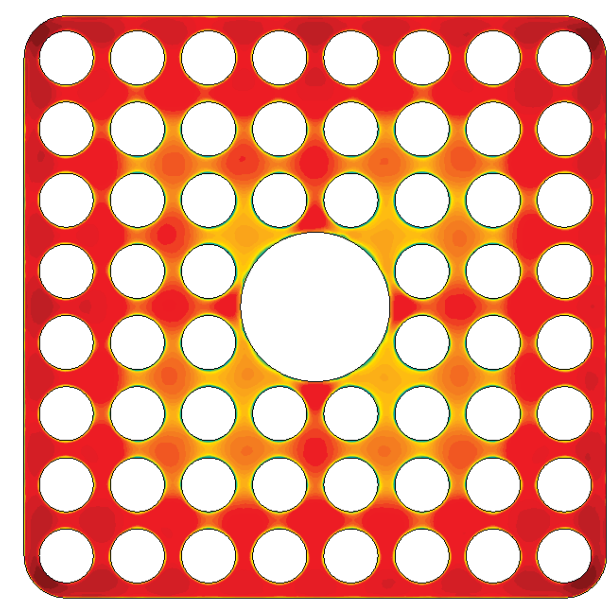

(a) $\operatorname{CFD}\left(\alpha_{\text {avg }}=85.53 \%\right)$
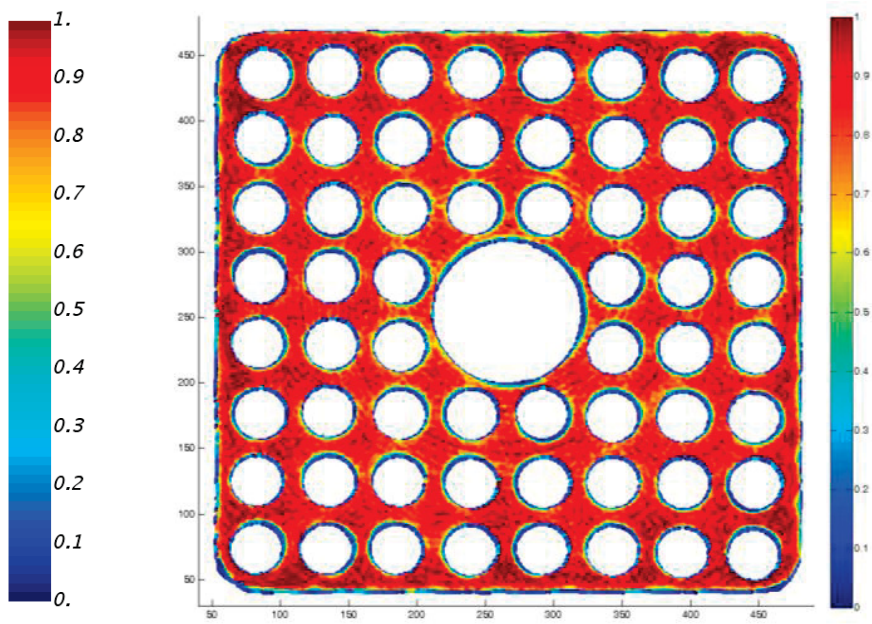

(b) Experiment $\left(\alpha_{\text {avg }}=80.64 \%\right)$

Figure 8. Comparison of void fraction distribution (BFBT 4101-61)

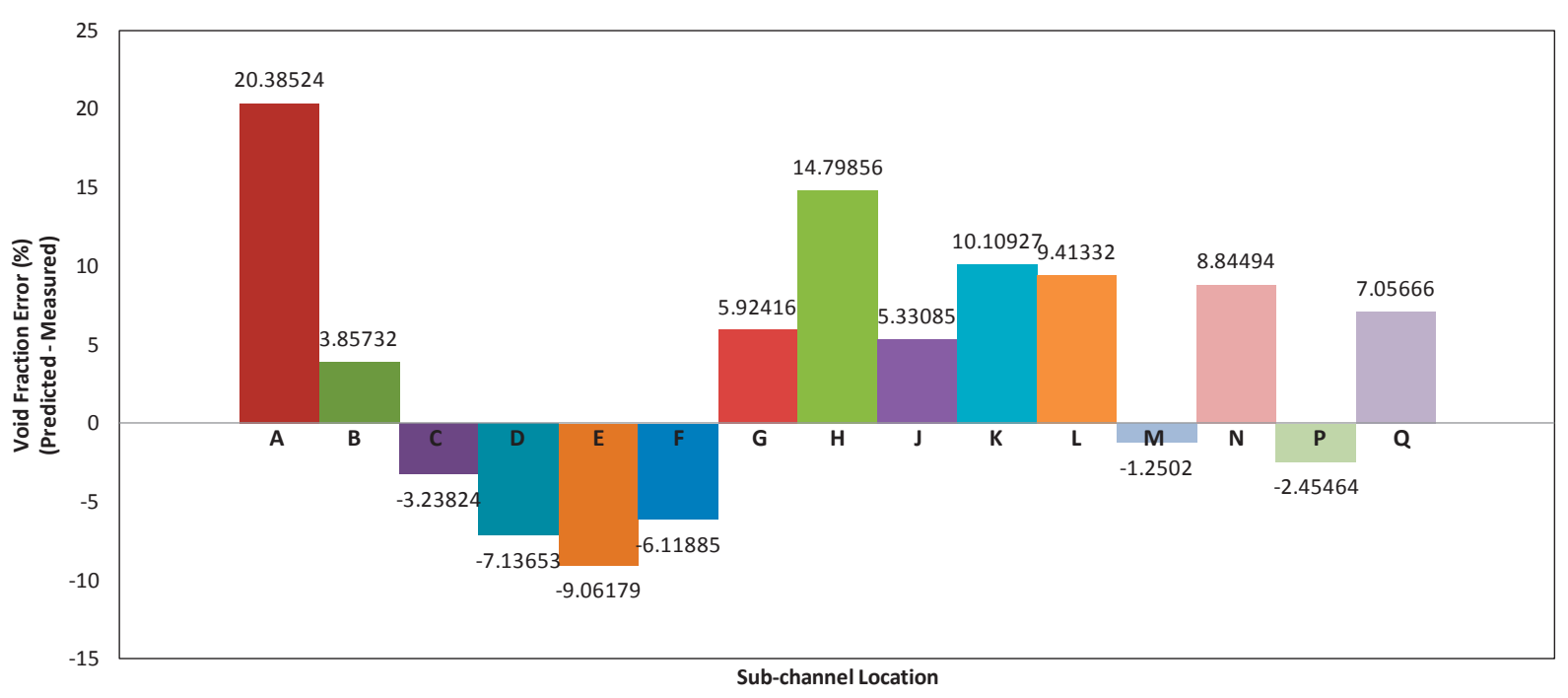

Figure 9. Deviation of sub-channel averaged void fraction (CFD vs. Experiment) 